\title{
RETRACTION
}

\section{Proteinase 3 (PR3) gene is highly expressed in CBF leukemias and codes for a protein with abnormal nuclear localization that confers drug sensitivity}

D Cilloni, S Carturan, C Maffè, F Messa, F Arruga, E Messa, M Pradotto, M Pautasso, C Zanone, P Fornaciari, I Defilippi, A Rotolo, E Greco, I lacobucci, G Martinelli, F Lo-Coco, E Bracco and G Saglio

Leukemia advance online publication, 8 April 2010; doi:10.1038/leu.2010.57

Retraction to: Leukemia; doi:10.1038/leu.2009.207

The authors of the above article would like to retract it. The paper contains inaccuracies in three figures (Figures 2a, $\mathbf{5}$ and $\mathbf{7 b}$ ), which, although similar to the original images and containing the same message, are not the original pictures referring to the experiments done.

The authors apologize to the readers, reviewers and editors of Leukemia for publishing these erroneous images. 